\title{
O SISTEMA AQÜÍFERO GUARANI - SAG
}

\author{
Aldo da Cunha Rebouças ${ }^{1}$ \\ Luiz Amore ${ }^{2}$
}

\begin{abstract}
The Guarani Aquifer System - GAS - consists of Triassic-Jurassic eolian-fluvio-lacustrine sandstones confined by Upper Jurassic- Late Cretaceous basalt flows. It covers about $1,195,500 \mathrm{~km}^{2}-839,800 \mathrm{~km}^{2}$ in Brazil; $225,500 \mathrm{~km}^{2}$ in Argentine; $71,700 \mathrm{~km}^{2}$ in Paraguay and $58,500 \mathrm{~km}^{2}$ in Uruguay - and is the largest transboundary confined aquifer system in the World. Althought the region might be well supplied with surface water resources, GAS countries currently encouter a range of water problems which have the potential to become much worse. Groundwater resources may be important as a source of irrigation water, water supplies, base flows to rivers, and in contributing to wetland water balance and ecology. The major policy considerations that emerged from the examination of GAS countries are that groundwater use should be managed both from the economic efficiency point of view and from the environmental point of view by safeguarding water potential and quality, mainly. Research should be an integral part of groundwater policy to reduce lack of information and to develop cost-effective technical solutions to groundwater pollution problems. The management objective for GAS resources should be long-term efficiency. This means that its quantity and quality should be maintained at an economically, socially and environmentally optimal level, taking into account the long-term uncertainties and the real long-term costs of controls on its use, protection and treatment.
\end{abstract}

\section{Introdução}

O Sistema Aqüífero Guarani - SAG - é a denominação dada pelo geólogo uruguaio Danilo Anton, em 1996, à unidade hidrogeológica da bacia sedimentar do Paraná/Chaco-Paraná formada pelos arenitos eólicos de idade Jurássica e os depósitos flúvio-lacustres de idade Triássica que ocorrem sob os derrames de rochas vulcânicas de idade Jurássico Superior e Cretáceo Inferior. Tendo em vista não haver solução de continuidade hidráulica entre estas distintas formações litológicas, o SAG caracteriza uma unidade hidroestratigráfica.

O SAG é o mais importante sistema aqüífero confinado transfronteiriço do mundo, cuja extensão no Brasil é da ordem de $839.800 \mathrm{~km}^{2}, 225.500 \mathrm{~km}^{2}$ na Argentina, $71.700 \mathrm{~km}^{2}$ no Paraguai e $58.500 \mathrm{~km}^{2}$ no Uruguai. A espessura média total desta camada aqüífera é de 277 m (ARAÚJO et al.,. 1999).

Outro fato, praticamente inusitado, é que - SAG tem água doce em toda a sua extensão e até as profundidades máximas já perfuradas de dois mil metros. Este sistema aqüífero foi lavado pelo menos 180 vezes desde o tempo da formação dos depósitos. Vários fatores contribuíram para esta situação, destacando-se a abundante pluviometria que ocorre na área desde o fim do Período Cretáceo e os levantamentos sucessivos das bordas da bacia sob a influência dos eventos que ocorreram durante o Terciário, onde destacam-se a neotectônica da Serra do Mar e da Cordilheira dos Andes.

Certamente, pelo fato da área de ocorrência do SAG ser muito rica de água nos rios, cuja descarga média dos sistemas hidrográficos do Paraná e Uruguai é de

\footnotetext{
${ }^{1}$ Consultor MMA/OEA/SRH

${ }^{2}$ Coordenador Nacional do Projeto Guarani, pelo Brasil - MMA/SRH
} 
$15.300 \mathrm{~m}^{3} / \mathrm{s}$, a extração das águas do SAG continua sendo feita de forma empírica e improvisada, desde o Período Colonial (1500-1822). Ultimamente, esta extração tem crescido, substancialmente, sobretudo no Brasil e no Uruguai, à medida que sua utilização constitui, regra geral, a alternativa mais barata de abastecimento das cidades, indústrias e desenvolvimento de instalações balneárias de águas aquecidas pelo gradiente geotérmico, principalmente.

Portanto, a importância social e econômica do SAG - seja para abastecimento público, industrial, laser e irrigação, principalmente - já não permite que se continue atuando na área na base da improvisação, empirismo e mistificação, sob o pretexto da falta de conhecimento hidrogeológico básico (Figura, 1).

\section{O Sistema Aqüífero Guarani - SAG}

O Sistema Aqüífero Guarani - SAG foi o nome dado pelo geólogo uruguaio Danilo Anton, em 1996, à unidade hidroestratigráfica formada pelos arenitos eólicos de idade Jurássica das Formações Botucatu no Brasil, Taquarembó na Argentina e Uruguai, Misiones no Paraguai e aos depósitos flúvio-lacustres de idade Triássica das Formações Pirambóia/Rosário do Sul no Brasil, Buena Vista na Argentina e Uruguai e Misiones no Paraguai (ROCHA, 1997).

Com cerca de $1.195 .500 \mathrm{~km}^{2}$, o SAG é um sistema aqüífero confinado, coberto sobre cerca de $90 \%$ da sua área de ocorrência pelos mais extensos derrames de rochas vulcânicas do mundo, os quais ocorreram na região durante o Jurássico Superior e Cretáceo Inferior. Estas rochas, basaltos em sua predominância, constituem a Formação Serra Geral na Argentina e Brasil, Alto Paraná no Paraguai e Arapey no Uruguai (Figura 2).

Durante o Cretáceo Superior, sobre o pacote de rochas vulcânicas depositaram-se as seqüências arenosas e argilosas alternadas do Grupo Buaru no Brasil, Formação Quebrada Monardes na Argentina, Formação Acaray no Paraguai e Formação Ascencio no Uruguai (ARAÚJO et. al., 1999).

O substrato hidrogeológico do SAG é formado pela seqüência alternada de siltitos e arenitos finos de idade Permo-Triássica denominada de Formação Rio do Rasto no Brasil, Formação Victorino Rodriques na 136
Argentina, sem denominação precisa no Paraguai e pela Formação Yaguary no Uruguai.

Neste contexto, a figura do "apontador de água", também chamado de radioestesista, ainda é freqüente. Este personagem caminha pela área em apreço segurando uma forquilha ou pêndulo de ebonite, parando quando o instrumento indica, segundo ele, que ali é um bom lugar para se perfurar um poço.

Certamente que poderá existir gente com sensibilidade sensorial inusitada, porém, recorre ao feiticeiro ou ao curandeiro da aldeia quem desconhece ou não tem meios de acesso à medicina que trata o problema de saúde em questão.

Assim, a prática empírica do "apontador de água" representa, regra geral, a tradicional mistificação que é engendrada pela falta de conhecimento hidrogeológico básico sobre os aspectos invisíveis relativos as condições de ocorrência, uso e conservação das águas subterrâneas, em geral, e do SAG, em particular.

\section{Origem da Água Subterrânea do SAG}

Os vários tipos de rochas da Bacia Geológica Sedimentar do Paraná e Paraná Chaco, cuja extensão atual é da ordem de 1,6 milhões de quilômetros quadrados, foram depositados ao longo do intervalo de tempo geológico que vai dos Períodos Siluriano (400 - 440 milhões de anos) ao Cretáceo (70 - 135 milhões de anos), principalmente. Os depósitos assim formados atingem espessuras já perfuradas de mais de $8.000 \mathrm{~m}$.

Ao longo desse longo intervalo de tempo, os ambientes de deposição foram ora dominantemente continentais, ora marinhos, nos quais formaram-se diferentes tipos de rochas, tais como arenitos, siltitos, argilas ou misturas em proporções variadas destes tipos litológicos. As características de porosidade/permeabilidade do pacote de sedimentos que preenche esta Unidade Geológica são do tipo intersticial e do tipo fissural, sobretudo, nos basaltos.

Neste quadro, portanto, poderá ocorrer nos sedimentos água subterrânea, ora salobra (teores de sólidos totais dissolvidos STD - entre 1000 e $10.000 \mathrm{mg} / \mathrm{L})$, ora salgada (STD maiores de $10.000 \mathrm{mg} / \mathrm{L}$ ).

Entretanto, as águas subterrâneas das camadas afetadas pela infiltração de parcela das precipitações atmosféricas - chuvas e 
neblinas, principalmente - são quase sempre doces (STD inferior a $1000 \mathrm{mg} / \mathrm{L}$ ) e as mais importantes. Estas águas meteóricas infiltradas podem ter lavado, inclusive, grandes compartimentos preenchidos de sedimentos formados em ambiente marinho, ou que foram afogados durante os períodos posteriores de transgressão ou invasão marinha. Desta forma, a água doce poderá ocorrer nos sedimentos marinhos, até as profundidades que foram atingidas pelas infiltrações de águas meteóricas que ocorreram ao longo dos tempos geológicos, pelos menos depois do último levantamento geral associado à formação da Cordilheira dos Andes.

Não obstante, as águas subterrâneas desta área são conhecidas apenas no nível preliminar. Esta situação resulta, fundamentalmente, do fato dos recursos hídricos de superfície terem sempre parecido serem muito abundantes na área. Como corolários, os milhares de poços já perfurados nos terrenos desta Bacia, não proporcionam, regra geral, informações suficientemente consistentes para discernimento de conhecimentos práticos ou científicos.

Entretanto, como já não existe, atualmente, limite técnico e econômico para a perfuração de poços profundos e extração de vazões de até um milhão de litros por hora, a racionalização do uso das águas subterrâneas do SAG tem que começar imediatamente, sob pena de não se ter condições de um desenvolvimento sustentável na sua área de ocorrência.

\section{Potencial Geotermal do SAG}

À medida que a água infiltrada no SAG atinge profundidades de milhares de metros, esta se aquece sob ação do gradiente geotérmico regional, cujo valor médio é da ordem de $1^{\circ} \mathrm{C} / 35 \mathrm{~m}$ de profundidade (TEISSEDRE; BARNER, 1981). Desta forma, um dos problemas que mais preocupa, em termos ambientais, principalmente, é o fato de que boa parte da água extraída do SAG chega à superfície com temperatura de $40^{\circ} \mathrm{C}$ até $80^{\circ} \mathrm{C}$, comparativamente, elevada em relação à temperatura do ambiente que varia entre $21^{\circ} \mathrm{C}$ e $23^{\circ} \mathrm{C}$ na maior parte da área. Desta forma, se águas que são extraídas de poços do SAG, depois de usadas nas instalações geotermais hidroterápicas, SPAs, indústrias e outras atividades, forem lançadas nos rios ainda, relativamente, quentes, pode-se engendrar sérios impactos na sua fauna e flora, principalmente, e no ambiente em geral.

Entretanto, a extração de água quente dos poços - cuja equação da reta determinada por correlação linear entre a temperatura da água na boca dos poços versus suas profundidades é $\mathrm{T}\left({ }^{\circ} \mathrm{C}\right)=0,0282$ $P(m)+22$ e coeficiente de correlação de 0,99 (TEISSEDRE; BARNER, 1981) poderá resultar em alternativas de uso da função geotermal do SAG. Esta função poderá significar grande economia de energia elétrica convencional. Por exemplo, a utilização das águas do SAG para produção de cerveja, onde se utiliza água com temperatura de $40^{\circ} \mathrm{C}$ para fermentar a cevada, significa zero de custo com o consumo de energia convencional para aquecer a água.

Assim, a utilização da água do SAG poderá não gerar energia elétrica, tendo em vista a sua baixa entalpia, mas poderá gerar, certamente, substancial economia de energia convencional (Figura 3).

Segundo ROSA FILHO et al., (2000), outras possibilidades de uso das águas quentes do SAG são a produção de ar condicionado, ativação de câmaras frigoríficas, secagem de produtos agrícolas, combate às geadas, desenvolvimento de processos industriais e a balneoterapia em instalações hidrotermais, tal como já vem ocorrendo em várias localidades nos estados de São Paulo, Paraná e Santa Catarina para pelar frango e porco, além é claro, do desenvolvimento do turismo associado ao funcionamento de instalações geotermais fisioterápicas e SPAs. Estas últimas aplicações são desenvolvidas, sobretudo, no Uruguai.

Numa avaliação preliminar, estima-se que a utilização da função geotermal do SAG representaria uma economia de 11 mil megawatts de energia, o que equivale a todo o potencial hidrelétrico atual instalado na bacia do Rio Paraná (REBOUÇAS, 1994).

Porém, essa função energética do SAG quase nunca foi sequer cogitada numa região relativamente rica em potencial hidrelétrico e ninguém lembra da alternativa de economizar energia com o uso daquela que ocorre de forma invisível e pouco fotogênica lá embaixo. 


\section{Aqüífero Transfronteiriço e Compartimentado}

O Sistema Aqüífero Guarani - SAG constitui o maior reservatório de água doce subterrânea transfronteiriço do mundo e de grande interesse para quatro países: Argentina, Brasil, Paraguai e Uruguai. Além disso, o SAG compreende a região, comparativamente, mais desenvolvida da América do Sul.

O SAG tem a vantagem de oferecer água de boa qualidade para os consumos doméstico, industrial e irrigação, principalmente. Além disso, em relação à captação, transporte e tratamento da água extraída dos rios, o custo da sua utilização é, regra gral, mais baixo, à medida que pode ser captada no local da própria demanda e a sua água não necessita ser, previamente, tratada para consumo doméstico, industrial ou agrícola.

Além disso, a contribuição dos fluxos subterrâneos provenientes dos diferentes sistemas aqüíferos desta Bacia Sedimentar - Grupo Bauru, zonas aqüíferas dos basaltos, SAG, camadas arenosas das Formações Rio do Rasto, Palermo, Rio Bonito, Aquidauana e Furnas, principalmente - alimentam o escoamento básico dos rios que drenam esta região, ou seja, aquele que ocorre durante as épocas de estiagem ou sem chuvas, perenizandoos.

Desta forma, a compartimentação tectônica que se observa da unidade geológica sedimentar, associa-se a compartimentação física engendrada pelas bacias hidrográficas que foram esculpidas nos seus terrenos. Como nestes contextos desenvolvem-se células de fluxos subterrâneos que alimentam as descargas de base dos rios, torna-se possível praticar a sua gestão integrada (Figura 4).

No Estado de São Paulo, o escoamento básico dos rios que drenam os terrenos da Bacia Geológica do Paraná RiosTurvo/Grande, Baixo e Médio Tietê, Peixe, São José dos Dourados, Baixo Paranapanema - representa cerca de 45\% das respectivas vazões totais, sendo as descargas mínimas de 70 a $75 \%$ do escoamento básico (DAEE, 1989).

Estas relações indicam a importância de se praticar uma gestão integrada da gota d'água disponível - rios, águas subterrâneas e de reuso, principalmente. $\mathrm{Na}$ parte brasileira, as descargas de base dos rios que drenam essa área indicam que as recargas diretas do SAG são da ordem de $160 \mathrm{~km}^{3} / a n o$, sendo que a recarga do Sistema Aqüífero Bauru cujo substrato hidrogeológico é formado pelo pacote de basaltos, atinge $74 \mathrm{~km}^{3} /$ ano (REBOUÇAS, 1976).

Assim, estimando-se que cerca de 25\% da recarga anual das águas subterrâneas poderiam ser extraídos do SAG, significa cerca de $68 \mathrm{~km}^{3} / a n o$, ou seja, uma quantidade suficiente para atender uma população de 68 milhões de habitantes, com uma taxa de uso total - doméstico, industrial e irrigação - per capita de $1000 \mathrm{~m}^{3} / a n o$.

Por sua vez, tendo em vista os mecanismos de filtração e autodepuração bio-geoquímica que ocorrem no subsolo, mormente nos quase $90 \%$ cobertos pelo pacote de basaltos, as suas águas apresentam-se limpas para beber.

Entretanto, a extensão total do SAG de $1.195 .500 \mathrm{~km}^{2}$, é compartimentada tanto em termos hidrológicos, quanto políticos e físico-ambientais. Assim, os $839.800 \mathrm{~km}^{2}$ que ocorrem no Brasil, ou seja, perto de $70 \%$ da extensão total são distribuídos por oito estados (213.200 $\mathrm{km}^{2}$ - MS; 157.600 $\mathrm{km}^{2}$ - RS; $155.800 \mathrm{~km}^{2}-\mathrm{SP} ; 131.300 \mathrm{~km}^{2}-$ PR; $\left(55.000 \mathrm{~km}^{2} \mathrm{GO} ; 51.300 \mathrm{~km}^{2}-\mathrm{MG}\right.$; $49.200 \mathrm{~km}^{2}$ - SC; e $26.400 \mathrm{~km}^{2}-\mathrm{MT}$. O SAG estende-se ainda por sobre 225.500 $\mathrm{km}^{2}$ na Argentina (19\%), $71.100 \mathrm{~km}^{2}$ no Paraguai (6\%) e $58.500 \mathrm{~km}^{2}$ no Uruguai $(5 \%)$.

Além disso, a importância relativa da sua extensão em cada país é também muito variável: de $10 \%$ do território brasileiro, $8 \%$ da Argentina, $18 \%$ do Paraguai, porém de quase $1 / 3$ do Uruguai. Assim, além da importância social e econômica diferenciada do SAG, tem-se que as suas áreas de ocorrência em cada um dos quatro países são também muito variadas.

Além disso, o SAG parece estar seriamente compartimentado em termos geológico/estruturais e que esta compartimentação engendra uma grande complexidade nos mecanismos de recarga, fluxo e descarga das águas subterrâneas associadas aos sistemas de fluxos locais, intermediários e regionais e, conseqüentemente, a gestão integrada de recursos hídricos e ambientais em geral dessa região (ROSA FILHO et al,. 2001). 
No nível atual dos conhecimentos geotectônicos disponíveis, identificam-se os compartimentos limitados pelas zonas de falhas geológicas ou lineamentos do Rio Verde, Guapiara, São Gerônimo - Curiúva, Rio Alonzo, Cândido de Abreu e Rio Piquiri, os quais são cortados transversalmente pela zona de falha que condiciona o desenvolvimento da calha atual do rio Paraná. Todos estes acidentes podem funcionar como zonas de recarga e de descarga, aumentando sobremaneira a dinâmica dos fluxos no Sistema Aqüífero Guarani - SAG. Além disso, os arcos Ponta Grossa e Rio Grande são feições estruturais importantes. As fontes de águas quentes e os diferentes teores de fluoretos (p.ex.) associados aos acidentes geológicos mais importantes, são indícios importantes que necessitam ser definidos.

Todos estes aspectos estão relacionados com a evolução geológico/estrutural da Bacia Sedimentar do Paraná/Chaco Paraná, a história dos fluxos subterrâneos, em particular os tempos de residência. Todos estes aspectos deverão ser analisados antes de se interpretar dados de poços produtores - tanto em termos quantitativos quanto qualitativos - e definir as condições de uso e conservação do ambiente e dos recursos hídricos da área em apreço.

\section{Gestão Integrada e Sustentável do SAG}

A água subterrânea do SAG foi alimentada, sobretudo, pela infiltração das chuvas que caíram na área em apreço, durante 0 longo intervalo de tempo geológico que nos separa do Período Triássico, ou seja, desde os tempos dos dinossauros.

Embora a água subterrânea do SAG já fosse captada por meio de fontes e poços escavados desde os primórdios do Período Colonial (1500 - 1822), sua importância econômica só foi reconhecida na década de 1950, especialmente nos estados de São Paulo e Rio Grande do Sul - Brasil (até hoje os maiores usuários das águas subterrâneas na Bacia do Paraná). Na década de 1970 foram iniciados os estudos preliminares que levaram a caracterização do seu grande potencial de água subterrânea (REBOUÇAS, 1976).

Por sua vez, foi também caracterizado que as duas unidades litoestratigráficas (arenitos eólicos e sedimentos flúvio- lacustres) situadas abaixo do pacote de basaltos da Bacia Geológica Sedimentar tinham nomes diferentes em distantes regiões no Brasil e em cada um dos países onde ocorriam (ROCHA, 1997).

Além disso, foi verificado que a água que escoa pela superfície e pelo subsolo dos terrenos da área constitui os seus recursos hídricos móveis, à medida que pode ser captada fora dos locais onde ocorreram às chuvas que lhes deram origem, sendo também chamada de Blue Water Flow.

Note-se que parcela de água precipitada da atmosfera que infiltrou no solo - chuvas e neblinas, principalmente - dá suporte ao desenvolvimento natural da cobertura vegetal natural ou cultivada, por isso também chamado de Green Water Flow.

No estado de São Paulo (p. ex.), o clima e balanço hídrico do solo indicam situação favorável ao desenvolvimento das culturas de verão, ou seja, durante os períodos sem chuvas no Estado, à medida que a sua reserva hídrica está próxima ou acima de $60 \%$ da capacidade máxima de retenção. Isto significa que, na área de ocorrência do SAG, as condições são altamente favoráveis à realização de práticas agrícolas e manejo do solo, aplicação de herbicidas, adubação em cobertura. Note-se, entretanto, que as condições que se apresentam favoráveis, hoje, à manutenção das práticas agrícolas, como colheita, plantio e aplicação de defensivos agrícolas, poderão ser afetadas, amanhã, pela forma desordenada de uso e ocupação do meio físico e ocorrência de chuvas que geram excedentes hídricos para escoamento e infiltração.

Por outro lado, até as últimas décadas do século passado, a ênfase dada pelos estudos de impacto ambiental (EIA) e pelos relatórios de impacto ambiental (RIMA) era o atendimento às exigências legais impostas pelas agências de fiscalização ambiental. Entretanto, os custos crescentes das atividades de abastecimento de água e de disposição dos efluentes, a consideração dos princípios usuário ou poluidor - pagador, principalmente, estabelecidos pela Lei Federal 9.433/97, levam à uma avaliação mais abrangente dos sistemas hídricos e das suas formas de uso.

Essa nova forma de abordagem tende a permitir que oportunidades de otimização do uso e proteção - quantitativa e qualitativa do SAG sejam identificadas, levando à introdução de práticas de gestão integrada 
da gota d'água disponível - captação de chuvas, rios, água subterrânea e reuso, principalmente.

Isso significa mudar radicalmente a cultura do setor, incluindo seu meio técnico, cujo pensamento, historicamente estabelecido é de que o aumento da oferta de água, mediante a construção de obras extraordinárias é a única solução para os problemas de recursos hídricos.

Entretanto, atender demandas hídricas crescentes por meio de um uso cada vez mais eficiente e integrado da gota d'água disponível - águas de chuva, rios, subterrâneas e de reuso, principalmente - é uma experiência de sucesso comprovado em muitos dos países relativamente mais desenvolvidos do mundo.

A partir daí, o objetivo maior da gestão dos recursos hídricos vem sendo à busca da eficiência da sua oferta e dos seus usos. Neste quadro, os gestores dos recursos hídricos deverão dar ênfase às situações onde o custo do uso das águas do SAG e de reuso dos efluentes líquidos, que, via de regra, exige um tratamento adequado, seja inferior ao preço da água superficial fornecida e ao preço dos esgotos coletados e tratados pelo sistema público ou privado, o que viabiliza economicamente essa solução.

$\mathrm{Na}$ verdade, do ponto de vista econômico e ambiental, não são raros os casos em que a introdução da prática de uso da água subterrânea, com do reuso dos esgotos e efluentes tratados, reduz para menos da metade, os custos com a água, mesmo quando a empresa se abastece de uma fonte própria.

Ao ganho econômico resultante dessa forma de abordagem juntam-se dois outros: O primeiro é de natureza operacional, pois se caracteriza à medida que a empresa, com a utilização da água subterrânea e o tratamento de efluentes para reuso, principalmente, acaba reduzindo os custos do princípio poluidor-pagador e dispondo de uma fonte alternativa de abastecimento, de extrema importância em regiões onde o fornecimento de água não é seguro ou onde a fonte própria da empresa - captação de rio ou de poço - está operando próximo ao limite. O segundo está ligado à sua imagem, já que o uso da água subterrânea e a prática do reuso de água acabam revelando a preocupação de reduzir a poluição ambiental representada pelo menor volume de descargas poluidoras.
Portanto, fica claro que é mais importante saber usar a gota d'água disponível, do que ostentar sua abundância.

Dada a diversidade hídrica e a extensão do território abrangido pelo SAG o Programa de Águas Subterrâneas deverá considerar aspectos relevantes tais como:

1) Promover o desenvolvimento sustentável dos recursos hídricos na área do SAG, tendo por base: i) levantamento do volume de água captado, extraído ou derivado (superficial ou subterrâneo); ii) o volume de água consumido (diferença entre o que é captado e o que é devolvido); iii) a carga de efluentes lançada nos corpos de água e os impactos das atividades agrícolas, industriais e do quadro sanitário das cidades dessa região.

2) Promover nos oitos estados onde o SAG ocorre, estudos hidrológicos nas suas bacias hidrográficas, para caracterizar a precipitação média $(P)$, o escoamento total (Qt), o rendimento $(\% \quad \mathrm{Qt} / \mathrm{P}), \quad 0$ escoamento básico (Qb), a vazão mínima $(\mathrm{Qm})$ e as relações percentuais (Qb/Qt) e (Qm/Qb) indicadoras da importância da contribuição das águas subterrâneas ao regime perene dos rios. Este conhecimento será de fundamental importância para se promover à gestão integrada da gota d'água disponível em cada uma das unidades de Gestão Integrada dos Recursos Hídricos UGRHI da área em apreço.

3) Promover nos estados da Federação onde ocorre o SAG a gestão integrada da gota d'água disponível e o seu uso cada vez mais eficiente, como uma ação de saúde pública e fator competitivo do mercado.

4) Promover a capacitação técnica da sociedade em geral, com ênfase nos educadores, gestores públicos e privados.

5) Promover o desenvolvimento de campanhas de informação e educação ambiental nos oitos estados onde o SAG ocorre, para mobilizar os diferentes segmentos da população sobre o alcance social e econômico de se realizar uma gestão integrada da gota d'água disponível - captação de chuvas, recarga artificial dos aqüíferos com águas de enchentes, coleta pluvial no meio urbano, reuso não potável no meio urbano, industrias e agricultura, principalmente. 
6) Promover o entendimento de que, se no início a ênfase era 0 atendimento às exigências legais impostas pelas agências de fiscalização ambiental, nos tempos atuais a palavra de ordem é a eficiência, levando a busca de:

- Maior produtividade por gota d'água disponível;

- Usos mais adequados dos recursos naturais em geral e da água em particular;

- Segurança e processos de usos doméstico, industrial e irrigação mais confiáveis;

- Melhoria da imagem perante o público nacional e internacional;

- Redução de impactos sobre o ambiente em geral.

Dependendo de circunstâncias regionais, a ênfase poderá ser dada a um ou outro desses fatores e, na área do SAG em geral deve-se buscar à racionalização do uso da água como forma de ganhar força para se atingir essas metas e se chegar à eficiência desejada.

Neste quadro, os princípios do usuáriopagador e do poluidor-pagador determinam que aos responsáveis pela degradação dos recursos naturais, em particular a água, devem ser imputados os custos relacionados às ações necessárias para que o ambiente permaneça em estado aceitável. Em outras palavras, estes princípios têm origem nos conceitos relativos à economia do bem-estar, segundo os quais, os preços dos bens e serviços na área do SAG deverão refletir integralmente os custos sociais, aí compreendidos os custos ligados à poluição, à exploração de recursos naturais em geral e da água em particular, e outras formas de degradação do ambiente.

\section{O Projeto Sistema Aqüífero Guarani}

Atualmente, assiste-se a um crescente aumento da extração das águas do SAG, graças ao grande progresso alcançado pelas técnicas de perfuração de poços, a performance das bombas e expansão da rede de distribuição de energia elétrica, principalmente, de tal forma que já não existe limitações para se extrair água de poços de qualquer profundidade e a baixo custo.

Estima-se que existam mais de dois mil poços perfurados no SAG no Brasil, com profundidades entre 100 e $300 \mathrm{~m}$, e algumas centenas de outros em seus domínios confinados, com profundidades entre 500 e $2.000 \mathrm{~m}$.

Apesar desses números, estima-se que a utilização das suas águas ainda é mínima, comparada ao seu potencial. Basta lembrar que a extração de apenas $25 \%$ da sua recarga anual daria para ofertar 1000 $\mathrm{m}^{3}$ /ano per capita a uma população de 68 milhões de habitantes no Brasil, ou seja, cerca de quatro vezes maior a atual.

Não obstante, nos últimos anos, sentiu-se a necessidade da ordenação do uso desses recursos hídricos, tendo em vista sua importância estratégica, social e econômica para os quatro países de seu domínio. Para evitar a possibilidade da ocorrência de super-extração e de contaminação e/ou poluição de suas águas, os governos dos países detentores da reserva - Argentina, Brasil, Paraguai e Uruguai - lançaram as bases para o desenvolvimento conjunto de um projeto de Proteção Ambiental e Gestão Sustentável do SAG. Esta proposta foi inicialmente elaborada pelos pesquisadores do Laboratório de Pesquisas Hidrogeológicas (LPH), da Universidade Federal do Paraná, sendo que no decorrer do tempo foi sendo acrescentadas alterações até ser submetido ao GEF Global Environmental Facility (fundo mundial para o meio ambiente).

O GEF aprovou uma verba de US\$14 milhões para financiar esta fase de estudos. O dinheiro será repassado pelo BIRD Banco Mundial e o projeto deverá ser tecnicamente gerido pela OEA Organização dos Estados Americanos e por órgãos de governo de cada país.

No Brasil, na sua primeira fase, a coordenação nacional do projeto estava afeta à Secretaria de Recursos Hídricos do Ministério do Meio Ambiente, sendo que atualmente está sendo coordenado pela ANA - Agência Nacional de Águas.

Os estudos estão previstos para durar 4 anos, a partir de meados do ano de 2002. Durante esse período será feito um levantamento técnico e científico, onde todos os poços serão cadastrados e colocados em bancos de dados. Deverá ser feita uma extensiva amostragem da água para se ter um conhecimento mais substancioso dos sistemas de fluxos de água no SAG, a fim de gerar regras de usos e conservação que sejam compatíveis a todos os países. 
Hoje, existem normas variadas em cada país e até mesmo em cada estado ou província. No Brasil, por exemplo, temos uma legislação de águas muito avançada, mas que só contempla, basicamente, a água dos rios e não aborda as águas subterrâneas.

Embora o SAG ocorra numa região onde a água superficial é abundante e a utilização da água subterrânea ainda seja insignificante em relação aos potenciais disponíveis, desde 1994, pelo menos, existe uma grande preocupação com os danos que uma crescente exploração desordenada do SAG representa, tanto em termos ambientais, quanto de uso e conservação dos recursos hídricos.

\section{Conclusões}

Lamentavelmente, as águas do SAG são invisíveis, escondidas, e as suas obras de captação pouco fotogênicas. Só aparece um poço. Não dá para inaugurar uma obra dessa.

Todavia, espera-se que o trabalho a ser desenvolvido pelo projeto SAG sirva para conscientizar as autoridades e a população em geral da região e dos respectivos países envolvidos, sobre o verdadeiro problema da região com relação à água, em particular e ao ambiente, em geral.

Em termos gerais, a América do Sul e o Brasil, em particular, ostentam as maiores descargas de águas nos seus rios, a mais exuberante cobertura vegetal e a maior biodiversidade do Planeta. Em termos de Pluviometria, a América do Sul tem uma média pluvial de cerca do dobro a de qualquer outro continente (REBOUÇAS et al., 1999).

Não obstante, temos grandes problemas de abastecimento d'água em todas as cidades da América do Sul e do Brasil. Nesse quadro, vale destacar que o fornecimento de água nas cidades do Brasil apresenta índices de perdas totais da água captada, tratada e injetada nas redes de distribuição que variam entre 30 e $60 \%$. Por sua vez, cerca de $64 \%$ das companhias estatais de saneamento básico, no Brasil, não coletam sequer os esgotos nas cidades abastecidas e nem se coleta e dispõe de forma adequada o lixo que se produz. Por sua vez, utilizam-se métodos de irrigação pouco eficientes - espalhamento superficial, pivô central e aspersão convencional - em 95\% dos 3 milhões de hectares irrigados no 142
Brasil, o que acaba gerando problema onde existe abundância de água superficial ou subterrânea.

Assim, o projeto do SAG, mesmo estando numa área onde, em princípio não há escassez de água, deverá nos proporcionar provas concretas de que é mais importante, atualmente, saber usar a gota d'água disponível do que ostentar abundância.

\section{Referências}

ARAÚJO, L. M., FRANÇA, A. B., POTTER, P. E. (1999). Hydrogeology of the Mercosul aquifer system in the Paraná d ChacoParaná Basins, South america, and comparison with the Navajo-Nugget aquifer system, USA. Hydrogeology Journal, 7, p. 317-336.

Departamento de Águas e Energia Elétrica DAEE, Estado de São Paulo (1987). Balanço hídrico do Estado de São Paulo, p 18-29.

REBOUÇAS, A. C., 1976, Recursos hídricos subterrâneos da Bacia do Paraná: Análise de pré-viabilidade.Tese de Livre Docência Universidade de São Paulo, 143 p.

REBOUÇAS, A. C., 1994, Gestão sustentável dos grandes aqüíferos. Anais 80 Cong. Brás.Águas Subterrâneas, p. 131139.

REBOUÇAS, A. C., 1999, Águas Subterrâneas, cap. 4, p. 117-151, in Águas Doces no Brasil: Capital Ecológico, Uso e Conservação,

REBOUÇAS; BRAGA; TUNDISI, Org. Coord. Científica, 717 p. IEA/ABC, São Paulo.

ROCHA, G. A., 1997, O grande manancial do Cone Sul. USP, Estudos Avançados $n^{\circ}$ 30. p. 191-212.

ROSA FILHO, E. F. DA; HINDI, E. C.; GIUSTI, D.A. \& MANTOVANI, L .E. (2000). Usos Potenciais do Hidrotermalismo do Sistema Aqüífero Guarani. Boletim Paranaense de Geociências, Curitiba. V. 48: p. 63-69. 
ROSA FILHO, E. F. DA; HINDI, E. C. (2001). Structural features and its consequences in the Guarani aquifer system. In: International Conference on Hydrological Challenges in Transbondary Water Resources Management. Koblenz-Alemanha, Anais. Bundesanstalt fuer Gewaesserkunde Federal Institute of Hydrology. p. 1-8.

ROSA FILHO, E.F. DA; HINDI, E.C.; GIUSTI, D.A.; NADAL, C.A.; XAVIER, J. M. (2001) Distribuição do Geotermalismo na Bacia
Sedimentar do Paraná. Revista Latinoamericana de Hidrologia para el Desarrollo. Curitiba, Brasil. Imprensa Universitária da UFPR. № 1: p.67-74.

TEISSEDRE, J. M., BARNER, U., 1981, Comportamento geotérmico e geoquímico das águas do aqüífero Botucatu na Bacia do Paraná. Rev. Águas Subterrâneas, $n^{\circ} \mathrm{IV}, \mathrm{p}$. 85-95. 